Purdue University

Purdue e-Pubs

CTRC Research Publications

Cooling Technologies Research Center

2015

\title{
Boiling Heat Transfer from an Array of Round Jets with Hybrid Surface Enhancements
}

M. Rau

Purdue University

S V. Garimella

Purdue University, sureshg@purdue.edu

E.M. Dede

Toyota

S. N. Joshi

Toyota

Follow this and additional works at: http://docs.lib.purdue.edu/coolingpubs

Rau, M.; Garimella, S V.; Dede, E. M.; and Joshi, S. N., "Boiling Heat Transfer from an Array of Round Jets with Hybrid Surface Enhancements" (2015). CTRC Research Publications. Paper 256.

http://dx.doi.org/DOI: 10.1115/1.4029969]

This document has been made available through Purdue e-Pubs, a service of the Purdue University Libraries. Please contact epubs@purdue.edu for additional information. 


\author{
Matthew J. Rau \\ School of Mechanical Engineering, \\ Purdue University, \\ 585 Purdue Mall, \\ West Lafayette, IN 47907
}

\section{Suresh V. Garimella ${ }^{1}$ \\ School of Mechanical Engineering, Purdue University, \\ 585 Purdue Mall, \\ West Lafayette, IN 47907 \\ e-mail: sureshg@purdue.edu}

\author{
Ercan M. Dede \\ Electronics Research Department, \\ Toyota Research Institute of North America, \\ 1555 Woodridge Avenue, \\ Ann Arbor, Ml 48105

\section{Shailesh N. Joshi \\ Electronics Research Department, Toyota Research Institute of North America, 1555 Woodridge Avenue, Ann Arbor, Ml 48105}

\section{Boiling Heat Transfer From an Array of Round Jets With Hybrid Surface Enhancements}

\begin{abstract}
The effect of a variety of surface enhancements on the heat transfer achieved with an array of impinging jets is experimentally investigated using the dielectric fluid HFE-7100 at different volumetric flow rates. The performance of a $5 \times 5$ array of jets, each $0.75 \mathrm{~mm}$ in diameter, is compared to that of a single $3.75 \mathrm{~mm}$ diameter jet with the same total open orifice area, in single-and two-phase operation. Four different target copper surfaces are evaluated: a baseline smooth flat surface, a flat surface coated with a microporous layer, a surface with macroscale area enhancement (extended square pin-fins), and a hybrid surface on which the pin-fins are coated with the microporous layer; area-averaged heat transfer and pressure drop measurements are reported. The array of jets enhances the single-phase heat transfer coefficients by 1.13-1.29 times and extends the critical heat flux $(\mathrm{CHF})$ on all surfaces compared to the single jet at the same volumetric flow rates. Additionally, the array greatly enhances the heat flux dissipation capability of the hybrid coated pin-fin surface, extending CHF by 1.89-2.33 times compared to the single jet on this surface, with a minimal increase in pressure drop. The jet array coupled with the hybrid enhancement dissipates a maximum heat flux of $205.8 \mathrm{~W} / \mathrm{cm}^{2}$ (heat input of $1.33 \mathrm{~kW}$ ) at a flow rate of $1800 \mathrm{ml} / \mathrm{min}$ (corresponding to a jet diameter-based Reynolds number of 7800) with a pressure drop incurred of only $10.9 \mathrm{kPa}$. Compared to the single jet impinging on the smooth flat surface, the array of jets on the coated pin-fin enhanced surface increased CHF by a factor of over four at all flow rates.
\end{abstract}

[DOI: 10.1115/1.4029969]

Keywords: jet impingement, jet arrays, boiling, two-phase cooling, heat transfer, surface enhancement, HFE-7100, microporous coating

\section{Introduction}

Liquid jet impingement, especially when combined with twophase operation, offers the potential for achieving excellent cooling performance while at the same time reducing the pumping power and energy usage in running the cooling loop itself. Still greater performance gains may be realized with the use of arrays of jets impinging on surfaces that are suitably engineered.

There has long been interest in using arrays of impinging jets to more effectively distribute the high heat transfer coefficients achieved with impinging jets [1-3]. In a design study comparing the size and number of jets in an array, Maddox and Bar-Cohen [4] concluded that a large number of small jets were advantageous for superior cooling capabilities at reduced pumping power compared to fewer, larger jets. Garimella and Schroeder [5] provided a direct experimental comparison between single jets and arrays of confined impinging air jets. In their comparison study, the diameter of the orifices in the arrays was identical to that of the single jets. Their study showed that jet arrays not only enhance the area-averaged heat transfer coefficient, but can also result in higher stagnation point peak heat transfer compared to a single isolated jet at a constant Reynolds number. When compared at a constant mass flow rate (which also resulted in a lower jet velocity for their array orifice geometries compared to the single orifices), the jet arrays provided a reduction in pressure drop several times greater than the corresponding reduction in area-averaged heat

\footnotetext{
${ }^{1}$ Corresponding author.

Contributed by the Heat Transfer Division of ASME for publication in the Journal of Heat Transfer. Manuscript received January 24, 2014; final manuscript received March 2, 2015; published online March 24, 2015. Assoc. Editor: Keith Hollingsworth
}

transfer coefficient. In one example case tested, a nine-jet array provided similar area-averaged heat transfer coefficients to that of a single jet but with a 36 times lower pressure drop. Arrays of jets are advantageous in two-phase operation as well, extending CHF and area-averaged heat transfer coefficients relative to single jets $[6,7]$.

Surface enhancements have been shown to greatly improve the single-phase cooling capability of single jets [8-10] and arrays of round jets [11]. Surface modifications targeted at boiling enhancement are also effective when paired with two-phase jet impingement. The impinging action of jets has been shown to extend CHF as compared to pool boiling on account of improved liquid replenishment and vapor removal from the heated surface [12-15]. These convective fluid transport mechanisms may be gainfully combined with boiling surface enhancement features, for which vapor clogging and limited liquid replenishment can present limitations (as reviewed in a companion paper [16]). Wadsworth and Mudawar [17] investigated boiling from miniature pin-fin and straight-fin heat sinks placed under an impinging slot jet; heat fluxes in excess of $100 \mathrm{~W} / \mathrm{cm}^{2}$ were achieved with a dielectric liquid at modest jet velocities. Copeland [18] experimentally investigated enhanced boiling heat transfer from micropin fins with two-phase jet impingement. For the jet arrays investigated, $\mathrm{CHF}$ increased with the number of nozzles in the jet arrays. In a study of hybrid macro/microscale surface enhancements, Lay and Dhir [19] showed the potential of finned surfaces designed to effectively evacuate vapor using the jet flow. The boiling heat transfer from a surface under a single impinging round jet was investigated for three macrostructured features: circumferential ridges, radial grooves, and radial fins. The radial fins provided the best nucleate boiling heat transfer and highest $\mathrm{CHF}$ at all jet 
velocities, and this was attributed to superior supply of liquid to the boiling surface.

In a recent investigation, Rau and Garimella [16] achieved significant increases in boiling heat transfer performance by combining impingement from a single jet and surfaces augmented with hybrid features of different scales. The hybrid enhancement studied combined the effects of increased nucleation sites by means of a microporous coating with area-enhancing extended surfaces. While limited investigations of such hybrid enhancements have been published for pool boiling [20-22] and jet impingement [19], they have not been studied in combination with arrays of impinging jets. Different enhanced surface structures are compared for their contribution to enhanced heat transfer from a $5 \times 5$ array of impinging jets of HFE-7100. The two-phase heat transfer and pressure drop are measured for four surfaces: a baseline smooth flat surface, a flat surface coated with a microporous layer, a surface with macroscale area enhancement (extended square pin-fins), and a hybrid surface on which pin-fins are coated with the microporous layer. The performance of the jet array is compared to that of a single jet with the same orifice open area, so that the total flow rate and jet velocity remain the same between the two sets of experiments.

\section{Experimental Setup}

2.1 Flow Loop and Test Section. The test facility used in this experimental study is identical to that reported in a companion paper where two-phase operation of a single jet impinging on enhanced surfaces was investigated [16]. Important details are summarized here. A magnetically coupled gear pump is used to circulate HFE-7100 $\left(k_{\mathrm{l}}=0.069 \mathrm{~W} / \mathrm{mK}, \rho=1481 \mathrm{~kg} / \mathrm{m}^{3}\right.$, $c_{\mathrm{p}}=1183 \mathrm{~J} / \mathrm{kg} \mathrm{K}, \mu=5.63 \times 10^{-4} \mathrm{~kg} / \mathrm{ms}$ at $25^{\circ} \mathrm{C}, T_{\text {sat }}=61^{\circ} \mathrm{C}$ at atmospheric pressure [23]) through the flow loop and test section. Volumetric flow rates are finely controlled by a metering valve and measured using turbine flowmeters with ranges of $100-1000 \mathrm{ml} / \mathrm{min}$ and $500-5000 \mathrm{ml} / \mathrm{min}$. The fluid temperature at the inlet to the test section is controlled by an upstream inline heater, while a liquid-to-air heat exchanger cools the fluid (condensing any vapor generated) after it exits the test section.

The boiling performance of HFE fluids is especially susceptible to oil contaminants, which can leach from elastomer seals used in the flow loop [24]. A carbon filter is used to remove any plasticizers and other organic contaminants from the fluid. An expandable reservoir and a membrane contactor are included to degas the fluid prior to testing as described in Ref. [16]. A $40 \mu \mathrm{m}$ particulate filter ensures that any particulates in the primary flow loop are removed.

A photograph of the confined and submerged jet impingement test section is shown in Fig. 1(a) (a cross-sectional diagram of the test section is presented in Ref. [16]). The test section, which is made from polyether ether ketone and polycarbonate, accommodates different orifice geometries, orifice-to-target spacings, and heat sources. For the current investigation, an orifice plate with a $5 \times 5$ array of $0.75 \mathrm{~mm}$ diameter $(d)$ orifices is used. The orifices, illustrated in Fig. 1(b), are spaced at a dimensionless pitch, $s / d$, of 4 and have a dimensionless orifice length, $l / d$, of 2 . The orifice-totarget spacing is controlled by resting the bottom of the plenum assembly, which can be translated vertically and is sealed by an O-ring on its outer diameter, on three precision-machined spacing pins. The $3 \mathrm{~mm}$-long pins used in the current investigation (yielding a dimensionless spacing, $H / d$, of 4 ) ensure that the confinement gap between the orifice plate and impingement surface is precisely defined and parallel.

A $T$-type thermocouple measures the fluid temperature just upstream of the jet orifice plate, which is taken as the jet inlet temperature. A differential pressure transducer with a $0-13.8 \mathrm{kPa}$ (calibrated uncertainty of $\pm 0.01 \mathrm{kPa}$ ) range measures the pressure drop across the orifice plate via pressure taps at the inlet temperature location and in the bottom wall of the test section chamber. A

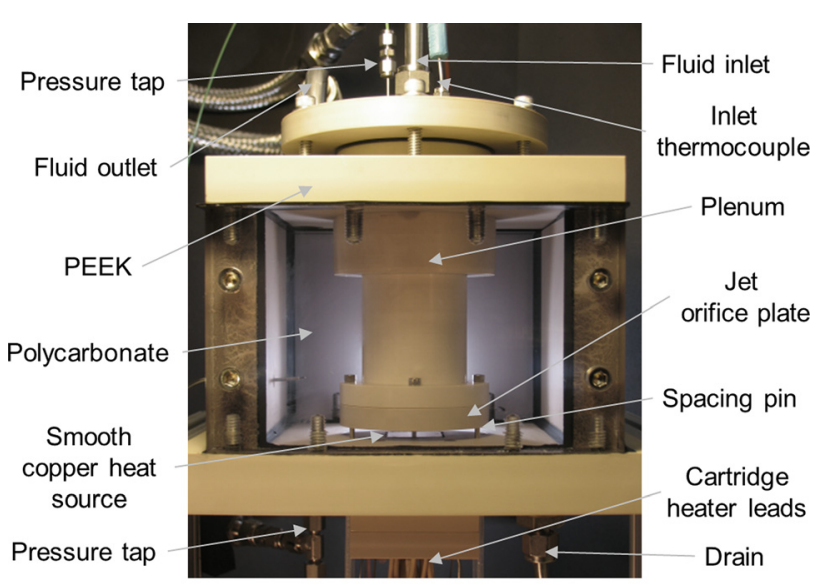

(a)

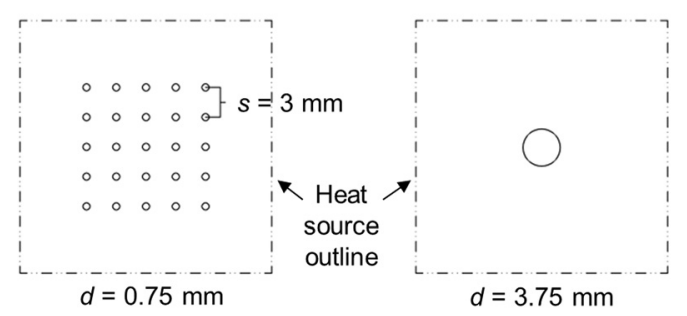

Fig. 1 (a) A photograph of the jet impingement test section, and (b) plan views of the single jet orifice from Ref. [16] (right) and current $5 \times 5$ jet orifice array (left) overlaid on a dashed, $25.4 \mathrm{~mm} \times 25.4 \mathrm{~mm}$, outline of the heat source. The diameters of the orifices in the $5 \times 5$ array are chosen such that the total open area of the array is equal to that of the single orifice.

gauge pressure transducer with a $0-103 \mathrm{kPa}$ (calibrated uncertainty of $\pm 0.13 \mathrm{kPa}$ ) range measures the pressure in the test section chamber.

The current study utilizes a copper block heat source powered by embedded cartridge heaters. The block is first installed into insulation components as described in Ref. [16] and then mounted into the bottom of the test section. The copper heat source is mounted and sealed such that a $25.4 \mathrm{~mm} \times 25.4 \mathrm{~mm}$ wetted area sits flush with the bottom of the test section chamber. Twelve $36 \Omega$ embedded cartridge heaters supply heat to the block, while four $T$-type thermocouples positioned along the axis of the block (spaced vertically at $2.54 \mathrm{~mm}$ intervals) allow calculation of the temperature gradient. The uncertainty in the thermocouple measurements is estimated to be $0.3{ }^{\circ} \mathrm{C}$ based on the bias errors of the calibration equipment and curve-fitting [16]. The surface temperature of the heating block is obtained by extrapolating the embedded thermocouple measurements, resulting in surface temperature uncertainties of $0.4{ }^{\circ} \mathrm{C}$ at low heat fluxes rising to approximately $1.5^{\circ} \mathrm{C}$ at $200 \mathrm{~W} / \mathrm{cm}^{2}$. The twelve cartridge heaters are powered by two, $1 \mathrm{~kW}$ DC power supplies (DCS, Sorenson) wired in series.

2.2 Surface Enhancements. The same enhanced surfaces that were evaluated with a single jet in Ref. [16] are tested in this study with the $5 \times 5$ array of impinging jets, as shown in Fig. 2 . The pin-fin surface consists of $0.5 \mathrm{~mm}$ wide square pin-fins, $2.5 \mathrm{~mm}$ tall, machined directly into the top surface of the copper heating block. The fins enhance the exposed area by a factor of three compared to the flat surface. Note that the fins are spaced such that the $0.75 \mathrm{~mm}$ diameter jets in the $5 \times 5$ array impinge between the square pin-fins. The two coated surfaces were created by coating the flat and pin-fin surfaces with a metallic microporous coating. The microporous metallic boiling enhancement coating made by $3 \mathrm{M}$ was chosen as it can be fused to threedimensional surface features without any applied pressure (the 

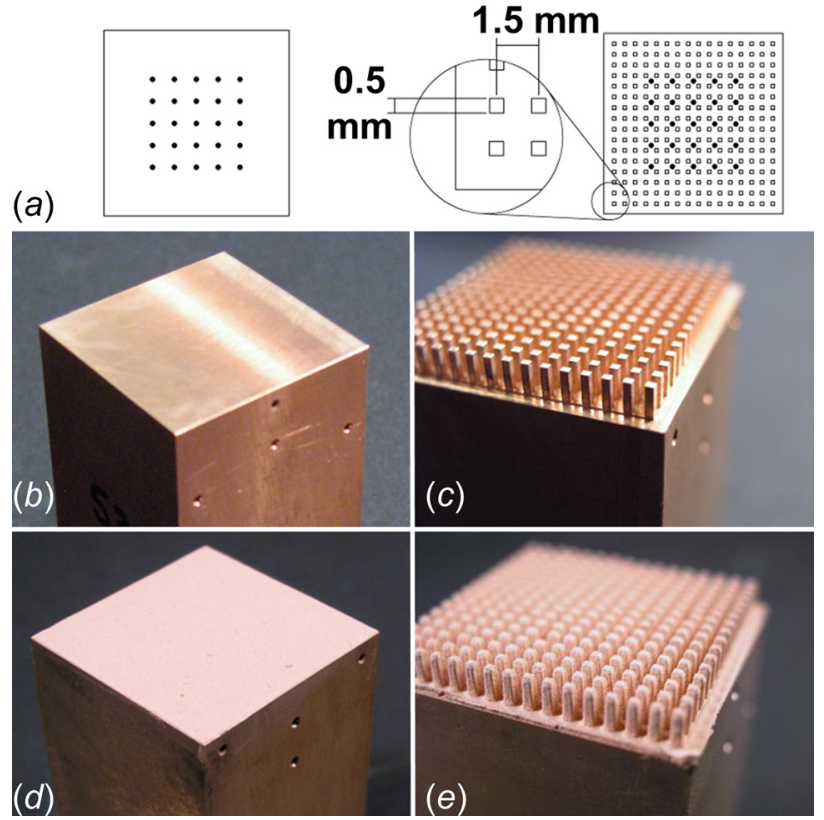

Fig. 2 (a) Schematic drawing of the flat and pin-fin surfaces with an overlay of the $5 \times 5$ jet array orifices, and photographs of $(b)$ the uncoated flat surface, $(c)$ uncoated pin-fin surface, (d) coated flat surface, and (e) coated pin-fins

firing procedure used is given in Ref. [16]). The coating consists of sub-20 $\mu \mathrm{m}$ diameter copper particles and is applied as an approximately $150 \mu \mathrm{m}$-thick layer uniformly to all wetted surfaces of the flat and pin-fin surfaces. The porosity of the coating was estimated by its powder weight-to-volume packing fraction prior to firing to be approximately $58 \%$. The coating is found to be very robust, as shown in the SEM images in Fig. 3. Figure 3(a) shows the coated pin-fin surface prior to any testing, while Fig. 3(b) shows the same surface after all of the experiments with the single jet in Ref. [16] and the $5 \times 5$ array of jets in the current study

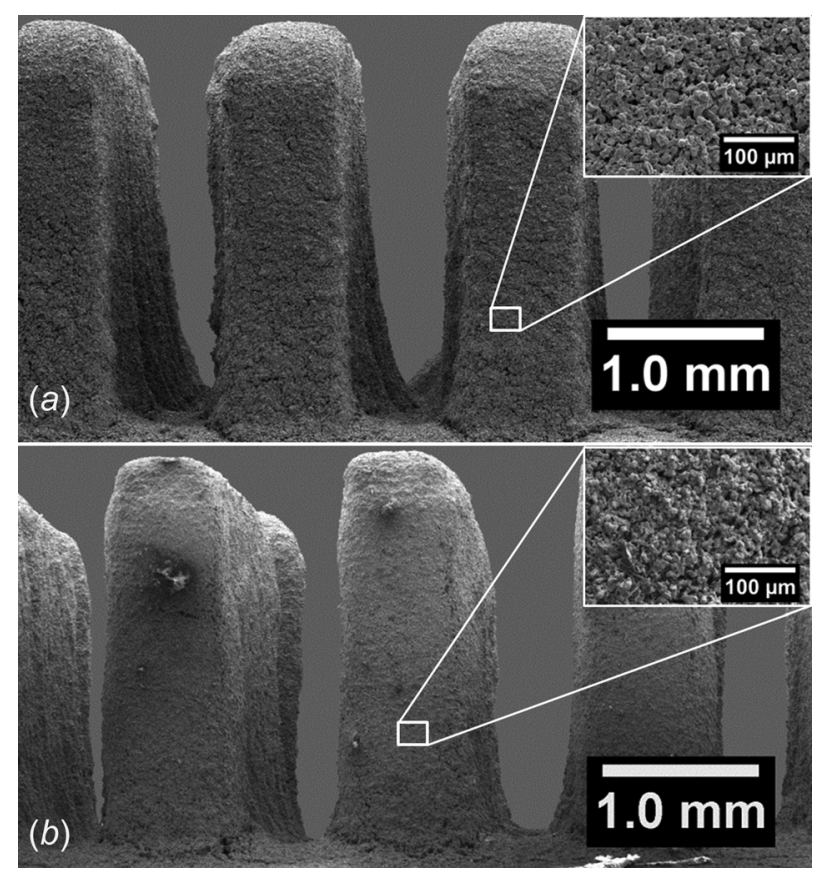

Fig. 3 SEM images of the coated pin-fins (a) before testing and $(b)$ after boiling from the surface for approximately $64 \mathrm{hr}$ were completed ( $\sim 64 \mathrm{hr}$ of testing under vigorous boiling conditions). No flaking or delaminating of the coating is observed.

The surfaces of the uncoated copper heating blocks are left in their as-machined condition. Characterization using an interferometric optical profiling system (NewView 7300, Zygo) shows that the machined flat and pin-fin surfaces have similar surface roughness $\left(R_{\mathrm{a}} \approx 0.5-0.7 \mu \mathrm{m}\right)$.

2.3 Experimental Procedures. Once the heating block is installed in the test section, the liquid in the flow loop is degassed prior to testing as described in Ref. [16]. The test surface is prepared by vigorously boiling it while immersed in the degassed HFE-7100 and allowing it to cool to ambient for $12-14 \mathrm{hr}$ while still immersed. This surface preparation consistently floods as many of the cavities on each surface as possible, so that the onset of nucleate boiling $(\mathrm{ONB})$ conditions observed in each test are uninfluenced by gas trapped on the surfaces [25].

After degassing, the fluid is circulated through the flow loop at the desired flow rate and heated to produce an inlet subcooling of $10^{\circ} \mathrm{C}$ using the inline heater. The fluid saturation temperature is calculated based on the pressure measured in the test section chamber. Once the desired operating conditions have been achieved, power to the cartridge heaters is incremented through the desired steps and steady-state data obtained at each heat flux by averaging over $4 \mathrm{~min}$ of readings. The expandable reservoir in the flow loop is used to maintain a constant operating pressure in the test section throughout testing, as described in Refs. [6,16].

For each case, testing begins in single-phase operation. The ONB is identified as a sudden reduction in the measured surface temperature, and also confirmed by visual observation of the formation of incipient bubbles. Due to the unpredictability of the $\mathrm{ONB}$, the surface temperature and heat flux at the ONB are extracted from the transient data as described in Ref. [16]. In every case, the heat flux is increased until CHF is achieved, an event that is marked by a large and sudden temperature rise for a very small increase in heater power. In some cases, the large temperature rise does not occur directly following the heater power increase, and the surface temperature and heat flux corresponding to $\mathrm{CHF}$ are extracted from the transient data (similar to the ONB determination) as described in Ref. [16]. When this gradual transition does not occur, CHF is reported as the last steady-state data point prior to the large temperature increase.

The surface temperature of the copper heating block, $T$, is calculated by extrapolating the embedded thermocouple measurements along its centerline, assuming one-dimensional conduction. The surface temperature determined with this method was confirmed to be a good approximation of the area-averaged surface temperature based on comparison to single-phase area-averaged jet impingement heat transfer correlations from the literature [26]. The heat flux entering the fluid is calculated from a $3 \mathrm{D}$ heat loss model, as described in Ref. [16]. The total heat loss, $q_{\text {loss }}$, is found to range from approximately $20 \%$ at low heat fluxes to $2 \%$ at the highest heat fluxes. The heat losses calculated from the model are then used to determine the area-averaged heat flux entering the fluid through the test surface, $q^{\prime \prime}$, according to

$$
q^{\prime \prime}=\frac{P-q_{\mathrm{loss}}}{A_{\mathrm{b}}}
$$

where $P$ is the electrical power input to the heater and $A_{\mathrm{b}}$ is the base surface area under consideration. Effective surface efficiencies, $\eta_{\mathrm{o}}$, for the pin-fin surfaces are calculated as

$$
\eta_{\mathrm{o}}=1-\frac{N A_{\mathrm{f}}}{A_{\mathrm{t}}}\left(1-\eta_{\mathrm{f}}\right)=\frac{q^{\prime \prime} A_{\mathrm{b}}}{h_{\mathrm{eff}} A_{\mathrm{t}} \Delta T_{\mathrm{b}}}
$$

where $N$ is the total number of fins, $A_{\mathrm{t}}$ is the total exposed surface area, $A_{\mathrm{f}}$ is the exposed area of one fin assuming a convective heat 
transfer tip condition, and $\Delta T_{\mathrm{b}}=T-T_{\mathrm{j}}$. The effective fin efficiency, $\eta_{\mathrm{f}}$, is calculated for a pin-fin with

$$
\eta_{f}=\frac{\tanh \left(m L_{c}\right)}{m L_{c}}
$$

where $m=\sqrt{4 h_{\mathrm{eff}} / k_{\mathrm{f}} w}$, and the corrected fin length is $L_{\mathrm{c}}=L+w / 4$. Equations (2) and (3) are iteratively solved to calculate $h_{\text {eff }}$ and $\eta_{\mathrm{o}}$. For consistency with two-phase jet impingement literature, the average heat transfer coefficient is referenced to the jet inlet temperature

$$
h=\frac{q^{\prime \prime}}{\left(T-T_{\mathrm{j}}\right)}
$$

The jet inlet temperature, $T_{\mathrm{j}}$, is maintained at $10^{\circ} \mathrm{C}$ below the fluid saturation temperature in all tests.

The experimental uncertainties are estimated as described in Ref. [16]. Based on the uncertainty in the flow meter reading and manufacturing tolerances of the jet orifices, the uncertainty in jet velocity is estimated to range from $0.03 \mathrm{~m} / \mathrm{s}$ to $0.1 \mathrm{~m} / \mathrm{s}$ from the lowest to highest flow rates, respectively. The uncertainty in the area-averaged convection coefficient is found to range from $11 \%$ at low heat fluxes to $2 \%$ at high heat fluxes and is shown for representative points in Fig. 4. The uncertainty in the calculated heat flux is estimated to be less than $2 \%$ using a $95 \%$ confidence interval and is shown for representative points in Figs. 5 and 6. The uncertainty in CHF is estimated as the uncertainty in the heat flux measurement plus half of the heat flux increment applied just prior to the temperature excursion. The uncertainty in the extrapolated surface temperature is the main contributor to error in this experiment.

\section{Results and Discussion}

The performance of a confined and submerged $5 \times 5$ array of round jets is reported for four surfaces: a baseline smooth flat surface, a flat surface coated with a microporous layer, a surface with macroscale area enhancement (extended square pin-fins), and a hybrid surface on which the pin-fins are coated with the microporous layer. Each orifice in the array has a diameter, $d$, of $0.75 \mathrm{~mm}$ and the orifice plate is positioned to maintain a orifice-to-target spacing, $H / d$, of 4 . This dimensionless spacing corresponds to a $3 \mathrm{~mm}$ gap between the heated surface and confining jet orifice plate, resulting in only a $0.5 \mathrm{~mm}$ gap between the tips of the

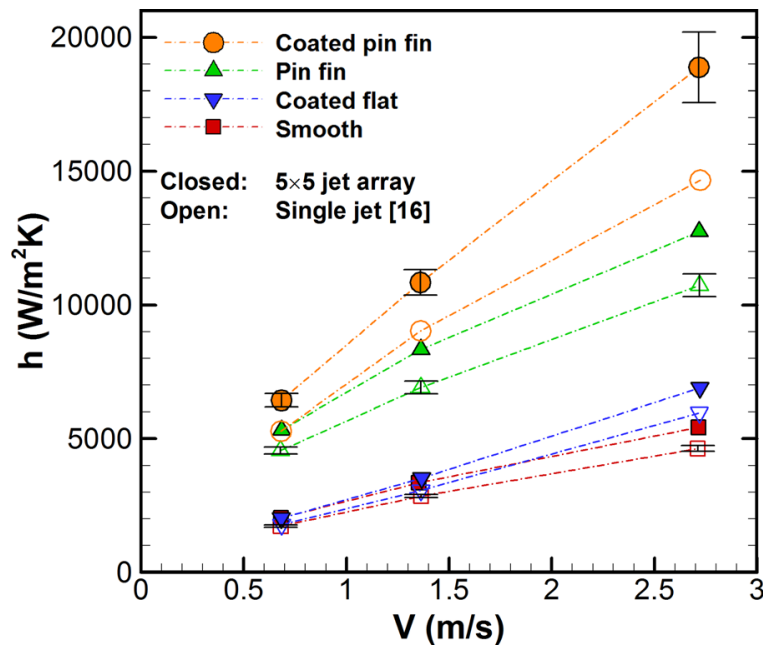

Fig. 4 Area-averaged single-phase heat transfer coefficient plotted as a function of jet velocity for the single jet [16] (open markers) and the array of impinging jets (closed markers) on all four surfaces considered

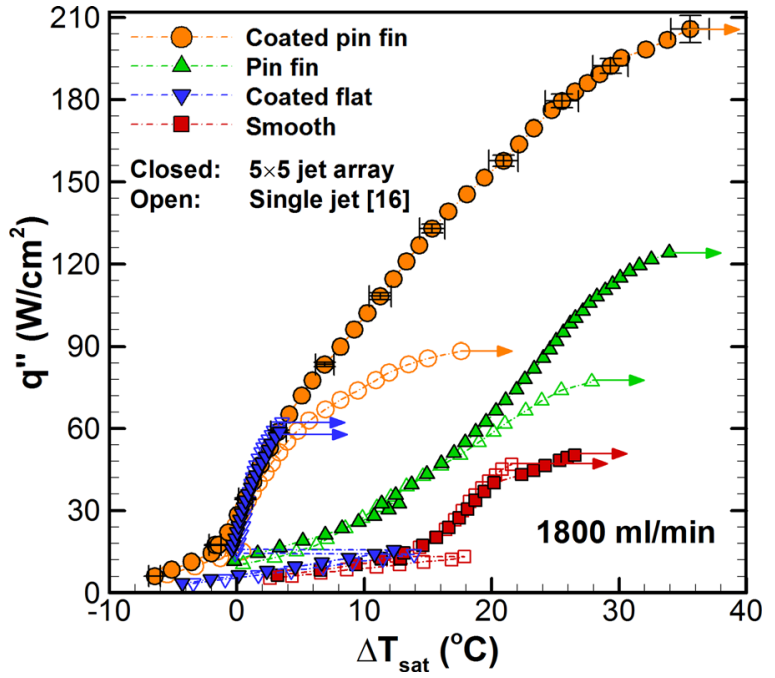

Fig. 5 Boiling curves for the single jet [16] (open markers) and the array of impinging jets (closed markers) on all four surfaces considered at a flow rate of $1800 \mathrm{ml} / \mathrm{min}$; arrows indicate the point at which CHF occurs

uncoated pin-fins and jet orifice plate. The experiments are conducted at three flow rates, 450,900 , and $1800 \mathrm{ml} / \mathrm{min}$, resulting in Reynolds numbers of 1900,3800 , and 7800, respectively.

In Rau and Garimella [16], experiments were performed with the same surfaces but with a single confined and submerged impinging round jet. The single jet orifice used in Ref. [16], shown in Fig. 1(b), has a diameter, $d$, of $3.75 \mathrm{~mm}$, and was maintained at a dimensionless orifice-to-target spacing, $H / d$, of 4 . The hybrid surface was found to greatly enhance heat transfer, and provided superior single-phase performance, displayed very low wall superheats in nucleate boiling, and enhanced $\mathrm{CHF}$ by 1.88-2.42 times depending on the flow rate. In the present work, the heat transfer capabilities and boiling characteristics with each surface type are compared with each other for the $5 \times 5$ array of impinging round jets, as well as with the single-jet data from Ref. [16].

3.1 Single-Phase Enhancement. The single-phase performance of the array of jets impinging on each surface is first presented and compared to that of the single jet to delineate the respective enhancement mechanisms. Figure 4 shows the average convection coefficient as a function of the jet velocity for both the $5 \times 5$ array and the single jet. For all surfaces, the convection coefficient from the array increases with increasing jet velocity as for the single jet. The array, however, provides an enhancement in heat transfer coefficient of 1.13-1.29 times relative to the single jet. It has been shown that arrays of small jets provide superior single-phase heat transfer compared to single jets of the same open area and velocity by distributing the peak stagnation-region convection coefficients across a larger area [6].

In single-phase operation, the addition of the porous coating on the flat surface does not appear to provide any overall enhancement for the array of jets except at the highest jet velocity. This enhancement is attributed to increased turbulence induced at the highest velocity by the greater roughness created by the particles in the coating layer [16,27], offsetting any small added conduction resistance of the thin metallic coating. The pin-fins, which increase the wetted surface area by 3 times, result in an enhancement in convection coefficient of 2.35-2.62 times relative to the smooth surface. The coated pin-fin surface displays the highest heat transfer enhancement in single-phase operation for the $5 \times 5$ array of jets (a total of 3.16-3.48 times compared to the baseline smooth surface). The superiority of this surface is explained by its gross area enhancement and increased surface roughness created by the coated pin-fins. Conformally coating the fins with the 

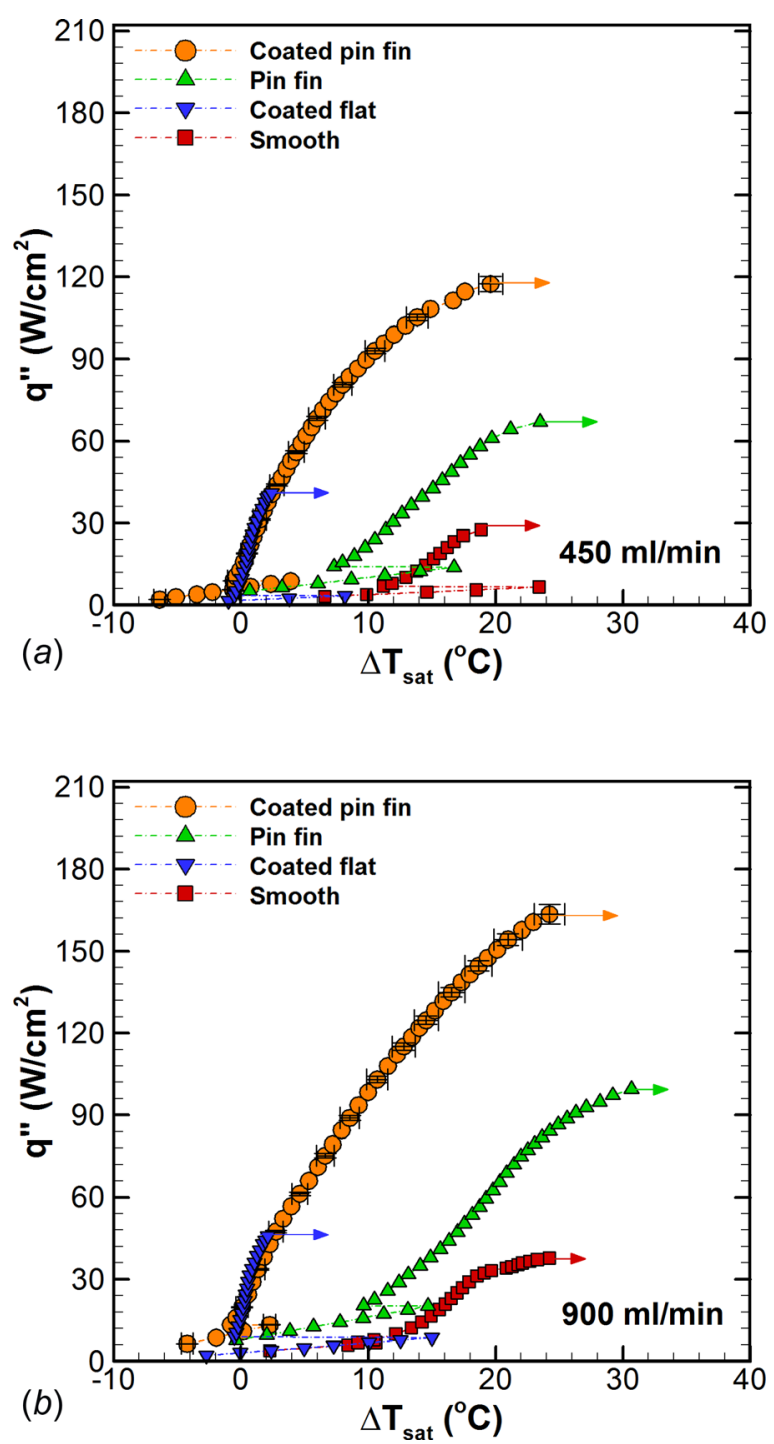

Fig. 6 Boiling curves for the array of impinging jets on all four surfaces at total flow rates of (a) $450 \mathrm{ml} / \mathrm{min}$ and (b) $900 \mathrm{ml} / \mathrm{min}$; arrows indicate the point at which CHF occurs

$150 \mu$ m-thick porous coating results in an additional $\sim 40 \%$ increase in surface area due to the effective enlargement of the three-dimensional fins. The added surface area, combined with the increased turbulence induced by the rough coating, is credited with the high single-phase performance of this surface with the array of jets.

3.2 Boiling Heat Transfer. The boiling curves presented in this work are referenced to the fluid saturation temperature, $T_{\text {sat }}$, for ease of comparison with the pool boiling literature. Figure 5 shows the boiling curves for the $5 \times 5$ array of jets and the single jet on each surface at a flow rate of $1800 \mathrm{ml} / \mathrm{min}$ (the arrow on each curve indicates the occurrence of $\mathrm{CHF}$ ). Each curve for the array of jets consistently overlaps with the single-jet curve in the fully developed nucleate boiling regime for a given surface type, displaying similar wall superheats for a given heat flux (e.g., $18{ }^{\circ} \mathrm{C}$ for both jet types at $30 \mathrm{~W} / \mathrm{cm}^{2}$ on the baseline smooth surface). The overlap in nucleate boiling results suggests that distributing the fluid through an array of orifices instead of a single orifice has little effect on the heat transfer at these heat fluxes and that boiling is the dominant heat transfer mechanism.

All surface enhancements provide superior heat transfer characteristics when compared to the smooth surface. Adding a porous coating to the flat surface results in a drastic reduction in wall superheat and a very steep slope for the boiling curve, a result that is consistent with many porous-surface boiling investigations $[19,25,28]$. The coating provides enhancement in boiling performance by creating many stable nucleation sites for bubbles to grow and depart from the surface. The addition of uncoated pin-fins also results in lower nucleate boiling wall superheats compared to the flat surface (by $\sim 6^{\circ} \mathrm{C}$ ), which is due to an increase in the wetted surface area and the number of nucleation sites.

The boiling curve for the hybrid coated pin-fin surface in Fig. 5 reflects a combination of the individual enhancement mechanisms. At low nucleate boiling heat fluxes just after ONB $\left(q^{\prime \prime} \approx\right.$ $20 \mathrm{~W} / \mathrm{cm}^{2}$ ), the coated pins display a slightly lower wall superheat than the coated flat surface. The lower wall temperature is a result of the additional convective heat dissipation resulting from the area-enhancing pin-fins, without any loss in performance for the thin metallic porous coating due to its high thermal conductivity. The coated pin-fins also display a slightly reduced slope in the fully developed nucleate boiling range compared to the coated flat surface, which is most evident at $900 \mathrm{ml} / \mathrm{min}$ (Fig. 6(b)). The reduced slope is observed for both the single jet and array of jets and is due to the added conduction resistance of the fins. The trends presented for fully developed nucleate boiling on all surfaces are consistent across all flow rates, as shown for the boiling curves in Figs. 5 and 6.

The effective surface efficiency for both the pin-fin and coated pin-fin surfaces under the jet array is plotted as a function of heat flux in Fig. 7; for comparison, data for the single jet impinging on the same surfaces at a flow rate of $1800 \mathrm{ml} / \mathrm{min}$ are also included as a dashed line. The surface enhancement type results in distinct grouping of the curves in the figure. The uncoated pin-fin surface cooled by the $5 \times 5$ array maintains a minimum surface efficiency of at least 0.76 , meaning that further gains in total heat transfer rate could be attained with further increases in surface area (e.g., with longer fins). The coated pin-fins have a noticeably lower effective surface efficiency, with a minimum value of 0.65 . The lower surface efficiency is caused by the higher effective heat transfer coefficients resulting from the porous coating in nucleate boiling. While an overall increase in heat transfer would still be realized with further increases in surface area for the coated fins, the relative gains would be lower than for the uncoated pin-fins. Both surfaces display an increase in effective surface efficiency toward the highest heat flux at a given flow rate. This increase is

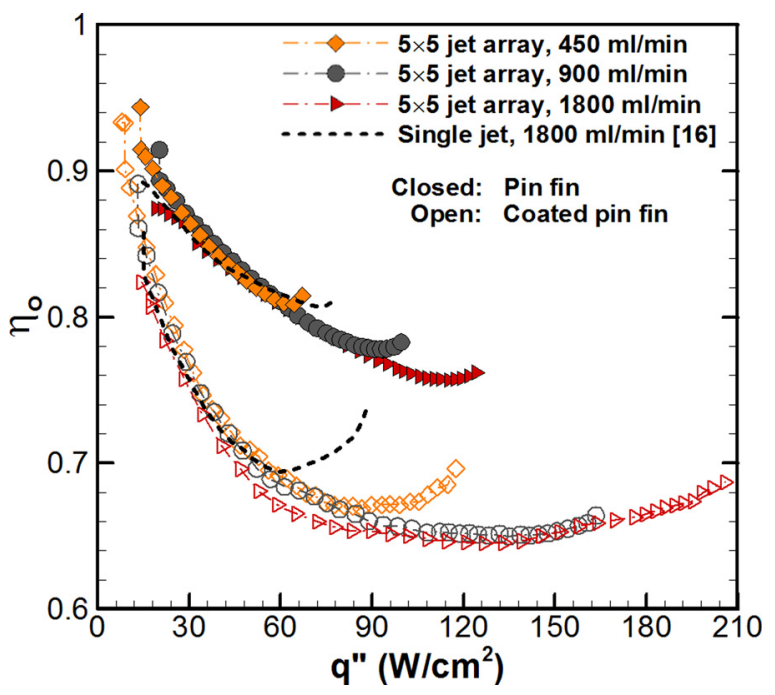

Fig. 7 Surface efficiency of the pin-fin (closed markers) and coated pin-fin (open markers) surfaces for the array of impinging jets at all flow rates, along with the single jet [16] results at $1800 \mathrm{ml} / \mathrm{min}$ 
Table 1 CHF for the single jet and $5 \times 5$ array of jets on the four target surfaces at all flow rates

\begin{tabular}{|c|c|c|c|c|c|}
\hline $\begin{array}{l}\text { Flow rate } \\
(\mathrm{ml} / \mathrm{min})\end{array}$ & Surface & $\begin{array}{c}\text { Single jet } q_{\mathrm{CHF}, \mathrm{SJ}}^{\prime \prime}[16] \\
\left(\mathrm{W} / \mathrm{cm}^{2}\right)\end{array}$ & $\underset{\left(\mathrm{W} / \mathrm{cm}^{2}\right)}{5 \times 5 \text { jet array }} q_{\mathrm{CHF}}^{\prime \prime}$ & $q_{\mathrm{CHF}}^{\prime \prime} / q_{\mathrm{CHF}, \mathrm{SJ}}^{\prime \prime}$ & $q_{\mathrm{CHF}}^{\prime \prime} / q_{\mathrm{CHF}, \mathrm{SJ}, \mathrm{S}}^{\prime \prime}$ \\
\hline \multirow[t]{4}{*}{450} & Smooth & 25.6 & 27.7 & 1.08 & 1.08 \\
\hline & Pin-fin & 54.6 & 67.1 & 1.23 & 2.62 \\
\hline & Coated flat & 37.5 & 40.9 & 1.09 & 1.60 \\
\hline & Coated pin-fin & 62.0 & 117.4 & 1.89 & 4.59 \\
\hline \multirow[t]{4}{*}{900} & Smooth & 30.3 & 37.8 & 1.25 & 1.25 \\
\hline & Pin-fin & 61.6 & 99.5 & 1.62 & 3.28 \\
\hline & Coated flat & 45.7 & 45.8 & 1.00 & 1.51 \\
\hline & Coated pin-fin & 68.0 & 163.4 & 2.40 & 5.39 \\
\hline \multirow[t]{4}{*}{1800} & Smooth & 46.9 & 50.2 & 1.07 & 1.07 \\
\hline & Pin-fin & 77.1 & 124.2 & 1.61 & 2.65 \\
\hline & Coated flat & 62.2 & 58.7 & 0.94 & 1.25 \\
\hline & Coated pin-fin & 88.3 & 205.8 & 2.33 & 4.39 \\
\hline
\end{tabular}

caused by a reduction in the effective heat transfer coefficient, likely due to dryout or vapor clogging at the base of the fins [16].

3.3 CHF. The greatest advantage of the $5 \times 5$ jet array compared to the single jet impinging on the surface enhancements is realized at the upper heat flux range for each surface. Table 1 lists the $\mathrm{CHF}$ values achieved with each surface at each flow rate tested by both the single jet $\left(q_{\mathrm{CHF}, \mathrm{SJ}}^{\prime \prime}\right)$ and $5 \times 5$ array of jets $\left(q_{\mathrm{CHF}}^{\prime \prime}\right)$. The relative enhancement in $\mathrm{CHF}$ for the $5 \times 5$ jet array compared to the single jet on each surface $\left(q_{\mathrm{CHF}}^{\prime \prime} / q_{\mathrm{CHF}, \mathrm{SJ}}^{\prime \prime}\right)$, as well as to the single jet on the baseline smooth flat surface $\left(q_{\mathrm{CHF}}^{\prime \prime} / q_{\mathrm{CHF}, \mathrm{SJ}, \mathrm{S}}^{\prime \prime}\right)$, is also listed in Table 1 . The array consistently increases CHF compared to the single jet on all surfaces except on the coated flat surface, leading to the conclusion that simply distributing fresh liquid to a wider area on the surface with the array of jets is not an effective CHF enhancement mechanism for flat surfaces coated with a microporous layer. In this case, CHF appears to be completely dominated by the presence of the porous coating, and insensitive to flow distribution.

Figure 8(a) shows CHF of the array of impinging jets and single jet as a function of jet velocity. On the flat surface, the jet array extends CHF past that achieved by the single jet at all velocities, which is consistent with the literature comparing single and arrays of jets of the same open area and size [6,7]. The CHF increases with increasing jet velocity in a near-linear fashion for all cases except the array of impinging jets on the pin-fin and coated pin-fin surfaces. Doubling the jet velocity from $0.68 \mathrm{~m} / \mathrm{s}$ to $1.36 \mathrm{~m} / \mathrm{s}$ has a noticeably larger effect on enhancing CHF for these two surfaces than a similar velocity increase on the flat and coated flat surfaces for either jet configuration. At $1800 \mathrm{ml} / \mathrm{min}$, the jet array in combination with the uncoated fins enhanced $\mathrm{CHF}$ by 1.61 times when compared to the same surface with the single jet. For the coated pin-fins at this flow rate, on the other hand, CHF more than doubled (from 88.3 to $205.8 \mathrm{~W} / \mathrm{cm}^{2}$ ) simply by switching from the single jet to the $5 \times 5$ array of jets.

The overall enhancement in CHF is presented in Fig. 8(b) relative to the single jet impinging on the baseline smooth flat surface $\left(q_{\mathrm{CHF}, \mathrm{SJ}, \mathrm{S}}^{\prime \prime}\right)$ at the same velocity (i.e., volume flow rate). For comparison between the two orifice arrangements, the single jet CHF on each surface (also normalized against that of the baseline surface) is also plotted. The addition of the surface enhancements alone increases CHF by as much as 2.42 times for the single jet compared to impingement on the smooth flat surface at the lowest jet velocity $(0.68 \mathrm{~m} / \mathrm{s})$, as seen for the coated pin-fins. The magnitude of enhancement decreases with increasing jet velocity and the coated pin-fins display an enhancement of 1.88 times at the maximum velocity $(2.72 \mathrm{~m} / \mathrm{s})$. This trend is consistent with the literature on boiling from extended surfaces $[17,18]$, where enhancement of CHF is generally less than the total area increase (area enhancement factor is 3 in the present case with the pin-fins).

The $5 \times 5$ array of jets displays relative CHF increases similar to the single jet with increasing jet velocity on the flat and coated flat surfaces. However, the extent of enhancement on the pin-fin and coated pin-fin surfaces is much greater than that achieved by the single jet. With the jet array, the pin-fins increase CHF by 2.62-3.28 times, and the coated pin-fins by as much as 5.39 times (and a minimum of 4.39 times), compared to the single jet on the flat surface. Both the pin-fin and coated pin-fin surfaces achieve
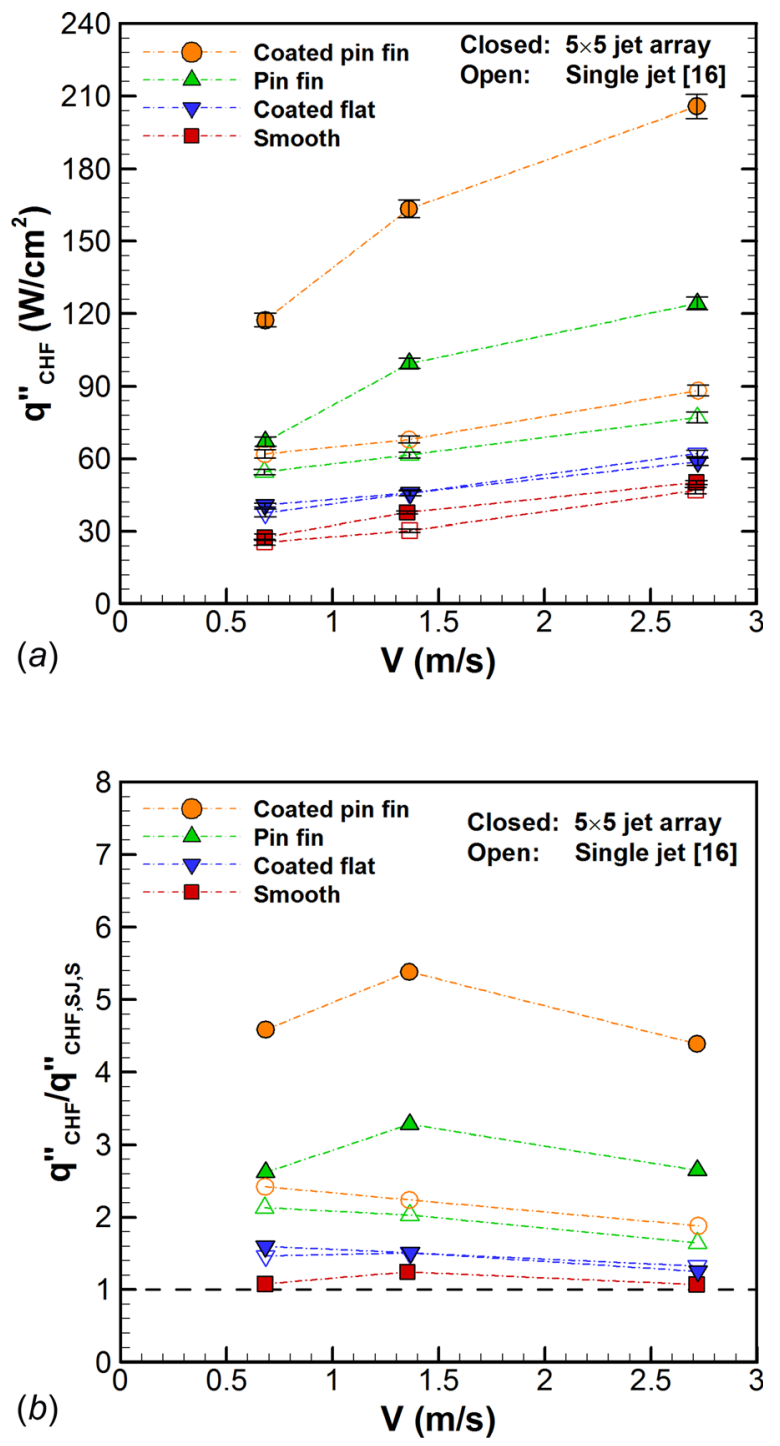

Fig. 8 (a) CHF for the single jet [16] (open markers) and $5 \times 5$ jet array (closed markers) and (b) CHF normalized with the single jet on the flat surface, as a function of jet velocity 

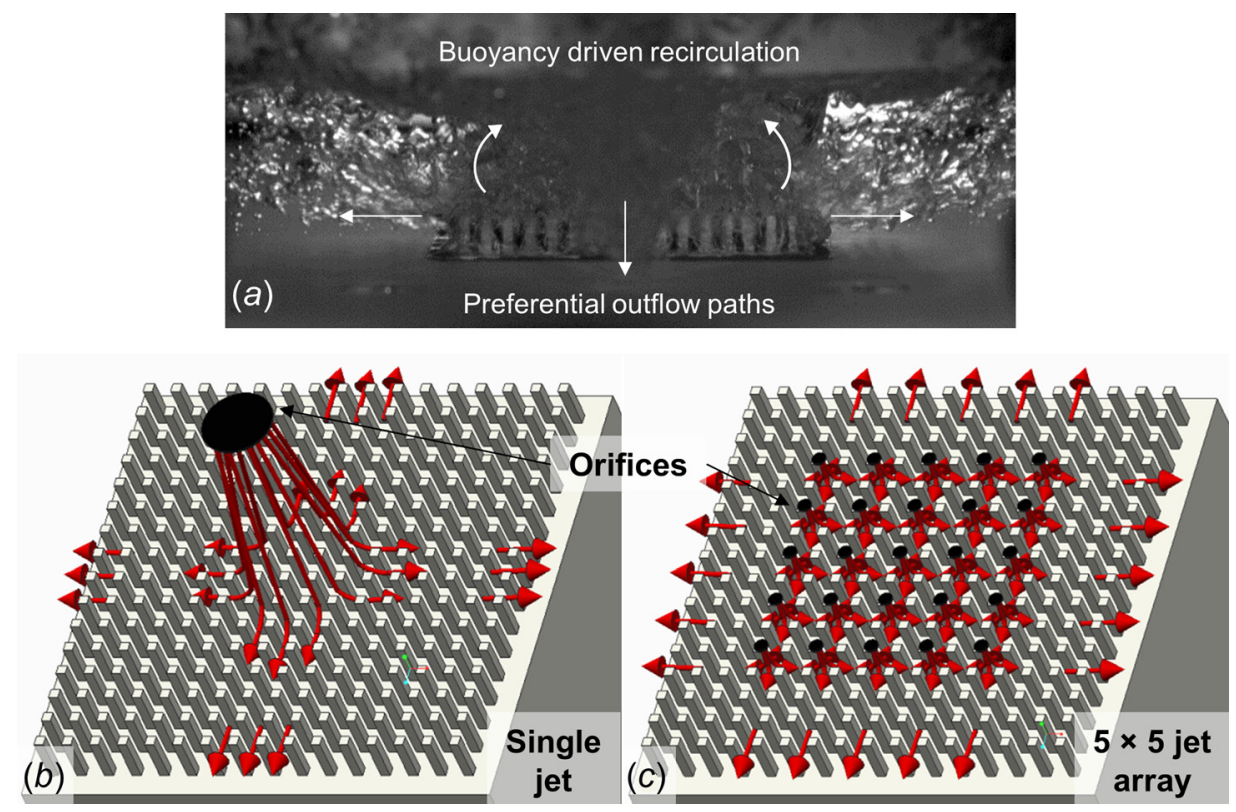

Fig. 9 (a) High-speed photograph of the single jet impinging at $1800 \mathrm{ml} / \mathrm{min}$ at a heat flux of $85.7 \mathrm{~W} / \mathrm{cm}^{2}$, and schematic drawings of the liquid distribution resulting from the $(b)$ single jet $[16]$ and $(c) 5 \times 5$ array of jets. Orifice position shown in black.

the greatest enhancement at a jet velocity of $1.36 \mathrm{~m} / \mathrm{s}$, pointing to the existence of an intermediate jet velocity where the enhancement effect is greatest.

The benefit of the array configuration can be explained based on the liquid replenishment and vapor evacuation characteristics of each impinging jet. Figure $9(a)$ shows a high-speed photograph taken of the single jet impinging on the coated pin-fin surface at $1800 \mathrm{ml} / \mathrm{min}$ and a heat flux of $85.7 \mathrm{~W} / \mathrm{cm}^{2}$. The single jet impinging at the center of the orthogonal array of pin-fins creates four preferential outflow paths through the fins for the impinging fluid, as shown schematically in Fig. 9(b). Large areas at the four corners of the heat sink are left relatively unaffected by the impinging flow. Vapor generated in these regions is not effectively evacuated from the heated surface, moves upwards due to buoyancy forces, and can be re-entrained into the impinging jet flow. In contrast, the $5 \times 5$ array of jets distributes liquid across a large-area of the surface (Fig. 9(c)). By comparing these schematic outflow paths, it is evident that a much greater area on the heated surface is exposed to the impinging and evacuating fluid flow with the jet array than with the single jet. While high-speed imaging of the desired quality could not be performed for the array due to the low orifice-to-target spacing of $3 \mathrm{~mm}$, the thermal performance makes it clear that the distribution of liquid by the array provides superior liquid replenishment and evacuates vapor more effectively from the pin-fin and coated pin-fin surface than does the single jet.

The array configuration thus beats the typically assumed limitation on the extent of heat transfer and CHF enhancement (that it cannot exceed the area enhancement ratio due to the extended surfaces) and actually achieves enhancements in CHF greater than the gross area enhancement afforded by the extended surfaces. The uncoated pin-fins provide 3 times greater surface area compared to the smooth surface, yet a 3.28 times greater CHF is realized with the jet array at a velocity of $1.36 \mathrm{~m} / \mathrm{s}$ when compared to the single jet on the smooth surface. The jet array with the coated pin-fins increases CHF still further, reaching a 5.39 times enhancement compared to the single jet on the smooth surface at this jet velocity.

3.4 Pressure Drop. The pressure drop resulting from the $5 \times 5$ array of jets in combination with all four surfaces at each flow rate is plotted as a function of heat flux in Fig. 10. This is also compared to the same data for the single jet [16]. For the single jet, the resulting pressure drop was previously found [16] to be constant with heat flux and is displayed by the horizontal flat line in Fig. 10. It is observed that the arrays of jets, even on the flat surface, yield a slightly higher pressure drop than that of the large single jet. These same arrays of orifices were characterized in Ref. [6] and it was concluded that burrs introduced during manufacturing of the orifices (which are much smaller in diameter for the array than for the single jet) were the most likely cause of the pressure drop difference. Otherwise, the same pressure drop should be expected because the $5 \times 5$ array has the same total open orifice area and jet velocity as the single orifice.

The flat surface and coated flat surface do not show any increase in pressure drop with heat flux (and vapor generation). As with the single jet, the pressure drop in these cases is dominated by the single-phase flow across the orifices, with a

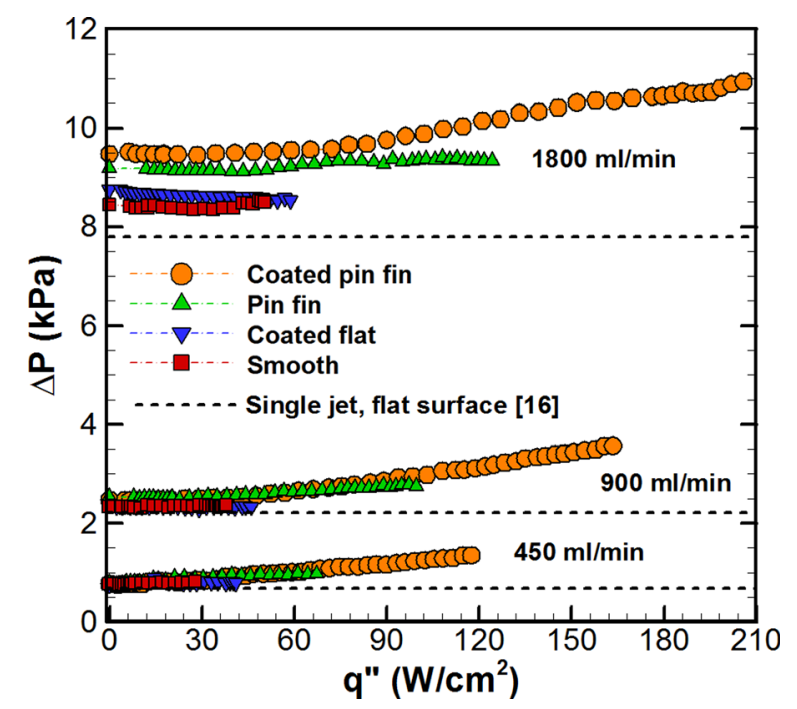

Fig. 10 Pressure drop as a function of heat input for the jet array on all surfaces at all flow rates 
negligible contribution of vapor flow in the confinement gap. The pin-fin and coated pin-fin surfaces, however, do show a slight increase in pressure drop with vapor generation. The $2.5 \mathrm{~mm}$-tall pin-fins fill a substantial portion of the $3 \mathrm{~mm}$-high confinement gap between the orifice plate and heated surface and the twophase outflow is much more restricted compared to the flat surface cases. With less flow area available, the vapor bubbles flowing out of the confinement gap have a measurable effect on the overall pressure drop.

Although the pin-fin and coated pin-fin surfaces display increases in pressure drop with increasing heat flux, the rise in pressure drop is still very modest in all cases, increasing by a maximum of only $0.6,1.1$, and $1.5 \mathrm{kPa}$ for the 450,900 , and $1800 \mathrm{ml} / \mathrm{min}$ cases, respectively. These modest rises correspond to relative increases of $75 \%, 44 \%$, and $15 \%$ from single-phase operation to CHF. The higher relative increase in pressure drop for the lower flow rates can be explained by the exit quality reached in each case. Based on the total heat input, including the sensible heat contribution from the $10^{\circ} \mathrm{C}$ inlet subcooling, the exit qualities at $\mathrm{CHF}$ are calculated to be $54 \%, 33 \%$, and $13 \%$ for the flow rates of 450,900 , and $1800 \mathrm{ml} / \mathrm{min}$, respectively. The lower flow rates result in a greater amount of vapor generation, leading to higher relative increases in pressure drop.

\section{Conclusions}

The two-phase heat transfer characteristics of a $5 \times 5$ array of jets $(d=0.75 \mathrm{~mm})$ of the dielectric liquid HFE-7100 impinging on a variety of surface enhancements is investigated: a flat surface coated with a microporous layer, a surface with macroscale area enhancement (extended square pin-fins), and a hybrid surface on which the pin-fins are coated with the microporous layer. The advantages of using jet arrays are highlighted by comparing to the performance of a single jet $(d=3.75 \mathrm{~mm})$ with the same open orifice area as the jet array. The heat transfer and pressure drop are measured with each of the different target surfaces at flow rates of 450,900 , and $1800 \mathrm{ml} / \mathrm{min}$.

The surface enhancements had similar effects for the array of jets as with the single jet, as investigated in Ref. [16]. The addition of the rough porous coating to the flat and pin-fin surfaces yielded an increase in single-phase convection coefficient at the highest jet velocities, due to increased turbulence in the wall-jet boundary layer. The additional surface area created by the pin-fins resulted in a single-phase enhancement of 2.35-2.62 times. The hybrid coated pin-fin surface provided the largest single-phase heat transfer enhancement for the array of jets at all flow rates due to its increased surface area and roughness. In twophase operation, the addition of pin-fins led to lower wall superheats (by $\sim 6^{\circ} \mathrm{C}$ ) in nucleate boiling and noticeably extended the upper heat flux limits of the array of jets. The addition of the porous coating to the flat and pin-fin surfaces drastically reduced the nucleate boiling wall superheats and significantly increased CHF.

Compared to the single jet, the array of jets was found to provide superior performance on all surfaces. The array achieved superior single-phase convection coefficients than the single jet, providing an increase of 1.13-1.29 times. Nucleate boiling wall superheats were found to be similar for both orifice configurations on each surface, where the dominant heat transfer mechanism was boiling; however, the array of jets extended CHF by $1.23-1.62$ times on the pin-fins and by $1.89-2.40$ times on the coated pin-fins compared to the single jet. The array of jets provides superior liquid distribution into the heat sinks with extended surfaces, resulting in greater evacuation of vapor from within the array of fins and effectively delaying dryout.

The combination of the hybrid enhancement with the array of jets provides high single-phase heat transfer coefficients, low surface superheats through much of the nucleate boiling regime, and a total enhancement in CHF of at least 4.39 times, and as much as 5.39 times, compared to the single jet on the flat copper surface. The high CHF achieved by the array comes at little cost in the form of increased operating pressure drop (a maximum increase of $1.5 \mathrm{kPa}$ was measured). The array of jets impinging onto the hybrid coated pin-fin surface represents an extremely effective cooling scheme capable of dissipating high heat fluxes from largearea devices. At a flow rate of $1800 \mathrm{ml} / \mathrm{min}$, the array of jets effectively dissipated $205.8 \mathrm{~W} / \mathrm{cm}^{2}$ at a pressure drop of only $10.9 \mathrm{kPa}$, resulting in a total heat dissipation of $1.33 \mathrm{~kW}$ from the heat source. The combination of low pressure drop and high heat dissipation makes impinging jet arrays in combination with boiling surface enhancements a very attractive approach for satisfying modern cooling demands while minimizing pumping power penalties.

\section{Acknowledgment}

The authors thank Toyota Motor Engineering and Manufacturing North America, Inc. for support of this work. The authors also thank Mr. Phillip Tuma of the $3 \mathrm{M}$ Company for applying the porous coating to the surfaces used in this work.

$$
\begin{aligned}
& \text { Nomenclature } \\
& A=\text { area } \\
& c_{\mathrm{p}}=\text { specific heat } \\
& d=\text { jet orifice diameter } \\
& h=\text { average heat transfer coefficient } \\
& H=\text { orifice-to-target spacing } \\
& k=\text { thermal conductivity } \\
& l=\text { length of orifice } \\
& L=\text { fin length } \\
& L_{\mathrm{c}}=\text { corrected fin length }(L+w / 4) \\
& N=\text { total number of fins } \\
& P=\text { electrical power input } \\
& q^{\prime \prime}=\text { average heat flux } \\
& q_{\mathrm{loss}}=\text { heat lost to the ambient } \\
& \mathrm{Re}=\text { Reynolds number }(\rho V d / \mu) \\
& T=\text { surface temperature } \\
& T_{\mathrm{j}}=\text { jet inlet temperature } \\
& T_{\mathrm{sat}}=\text { saturation temperature of the fluid } \\
& V=\text { jet velocity } \\
& w=\text { fin width } \\
& \Delta P=\text { pressure drop }
\end{aligned}
$$

\section{Greek Symbols}

$\eta_{\mathrm{f}}=$ effective fin efficiency

$\eta_{\mathrm{o}}=$ effective surface efficiency

$\mu=$ dynamic fluid viscosity

$\rho=$ fluid density

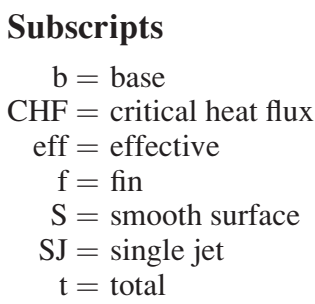

\section{References}

[1] Martin, H., 1977, "Heat and Mass Transfer Between Impinging Gas Jets and Solid Surfaces," Adv. Heat Transfer, 13, pp. 1-60.

[2] Goldstein, R. J., and Timmers, J. F., 1982, "Visualization of Heat Transfer From Arrays of Impinging Jets," Int. J. Heat Mass Transfer, 25(12), pp. 1857-1868.

[3] Huber, A. M., and Viskanta, R., 1994, "Effect of Jet-Jet Spacing on Convective Heat Transfer to Confined, Impinging Arrays of Axisymmetric Air Jets," Int. J. Heat Mass Transfer, 37(18), pp. 2859-2869.

[4] Maddox, D. E., and Bar-Cohen, A., 1994, "Thermofluid Design of Single-Phase Submerged-Jet Impingement Cooling for Electronic Components," ASME J. Electron. Packag., 116(3), pp. 237-240. 
[5] Garimella, S. V., and Schroeder, V. P., 2001, "Local Heat Transfer Distributions in Confined Multiple Air Jet Impingement," ASME J. Electron. Packag., 123(3), pp. 165-172.

[6] Rau, M. J., and Garimella, S. V., 2013, "Local Two-Phase Heat Transfer From Arrays of Confined and Submerged Impinging Jets," Int. J. Heat Mass Transfer, 67, pp. 487-498.

[7] Copeland, D., 1998, "Single-Phase and Boiling Cooling of a Small Heat Source by Multiple Nozzle Jet Impingement," Int. J. Microelectron. Packag., 1(2), pp. 105-113.

[8] Brignoni, L. A., and Garimella, S. V., 1999, "Performance Characteristics of Confined Impinging Air Jets With Surface Enhancement," ASME Adv. Electron. Packag., 26(2), pp. 2009-2014.

[9] Brignoni, L. A., and Garimella, S. V., 1999, "Experimental Optimization of Confined Air Jet Impingement on a Pin-Fin Heat Sink," IEEE Trans. Compon. Packag. Technol., 22(3), pp. 399-404.

[10] El-Sheikh, H. A., and Garimella, S. V., 2000, "Enhancement of Air Jet Impingement Heat Transfer Using Pin-Fin Heat Sinks," IEEE Trans. Compon. Packag. Technol., 23(2), pp. 300-308.

[11] El-Sheikh, H. A., and Garimella, S. V., 2000, "Heat Transfer From Pin-Fin Heat Sinks Under Multiple Impinging Jets," IEEE Trans. Adv. Packag., 23(1), pp. 113-120.

[12] Monde, M., 1987, "Critical Heat Flux in Saturated Forced Convection Boiling on a Heated Disk With an Impinging Jet,” ASME J. Heat Transfer, 109(4), pp. 991-996.

[13] Ma, C.-F., and Bergles, A. E., 1983, "Boiling Jet Impingement Cooling of Simulated Microelectronic Chips," Heat Transfer Electron. Equip., HTD, 28, pp. 5-12.

[14] Zhou, D. W., and Ma, C.-F., 2004, "Local Jet Impingement Boiling Heat Transfer With R113," Heat Mass Transfer, 40(6-7), pp. 539-549.

[15] Mitsutake, Y., and Monde, M., 2003, "Ultra High Critical Heat Flux During Forced Flow Boiling Heat Transfer With an Impinging Jet," ASME J. Heat Transfer, 125(6), pp. 1038-1045.

[16] Rau, M. J., and Garimella, S. V., 2014, "Confined Jet Impingement With Boiling on a Variety of Enhanced Surfaces," ASME J. Heat Transfer, 136(10), p. 101503.

[17] Wadsworth, D. C., and Mudawar, I., 1992, "Enhancement of Single-Phase Heat Transfer and Critical Heat Flux From an Ultra-High-Flux Simulated
Microelectronic Heat Source to a Rectangular Impinging Jet of Dielectric Liquid,” ASME J. Heat Transfer, 114(3), pp. 764-768.

[18] Copeland, D., 1996, "Single-Phase and Boiling Cooling of Small Pin-Fin Arrays by Multiple Nozzle Jet Impingement," ASME J. Electron. Packag., 118(1), pp. 21-26.

[19] Lay, J. H., and Dhir, V. K., 1995, "Nucleate Boiling Heat Flux Enhancement on Macro/Micro-Structured Surfaces Cooled by an Impinging Jet," J. Enhanced Heat Transfer, 2(3), pp. 177-188.

[20] Rainey, K. N., and You, S. M., 2000, "Pool Boiling Heat Transfer From Plain and Microporous, Square Pin-Finned Surfaces in Saturated FC-72," ASME J. Heat Transfer, 122(3), pp. 509-516.

[21] Nakayama, W., Nakajima, T., and Hirasawa, S., 1984, "Heat Sink Studs Having Enhanced Boiling Surfaces for Cooling of Microelectronic Components," ASME Paper No. 84-WA/HT-89.

[22] Chang, J. Y., and You, S. M., 1997, "Enhanced Boiling Heat Transfer From Micro-Porous Cylindrical Surfaces in Saturated FC-87 and R-123," ASME J. Heat Transfer, 119(2), pp. 319-325.

[23] 3M, 2002, 3M Novec Engineered Fluid HFE-7100 for Heat Transfer, 3M, St. Paul, MN, pp. 1-8.

[24] Tuma, P. E., 2011, "Design Considerations Relating to Non-Thermal Aspects of Passive 2-Phase Immersion Cooling," Proceedings of the 27th Annual IEEE Semiconductor Thermal Measurement and Management Symposium, San Jose, CA, pp. 1-9.

[25] Marto, P. J., and Lepere, Lt. V. J., 1982, "Pool Boiling Heat Transfer From Enhanced Surfaces to Dielectric Fluids," ASME J. Heat Transfer, 104(2), pp. 292-299.

[26] Li, C.-Y., and Garimella, S. V., 2001, "Prandtl-Number Effects and Generalized Correlations for Confined and Submerged Jet Impingement," Int. J. Heat Mass Transfer, 44(18), pp. 3471-3480.

[27] Moreno, G., Narumanchi, S., Venson, T., and Bennion, K., 2013 "Microstructured Surfaces for Single-Phase Jet Impingement Heat Transfer Enhancement," ASME J. Therm. Sci. Eng. Appl., 5(3), p. 031004.

[28] Webb, R. L., 1983, "Nucleate Boiling on Porous Coated Surface," Heat Transfer Eng., 4(3-4), pp. 71-82. 